\title{
Sigma Ratings: Adapting the Credit Rating Agency Model for the Anti-Money Laundering World
}

Purpose: Sigma Ratings is a new entrant to the AML marketplace and seeks to alleviate some of the inherent flaws within the AML regime. This paper exists to examine those flaws and ask whether Sigma may succeed in this bourgeoning marketplace.

Design/Methodology: This paper is based upon a normative methodology, which takes place after reviewing the relevant literature in order to examine the potential success for Sigma Ratings.

Findings: The paper finds that there is indeed a position for Sigma Ratings in the marketplace, and that it may alleviate key issues within the AML Regime.

Originality: The paper presents Sigma Ratings to the literature for the first time and positions this against an examination of the role of banks within AML - Sigma's main demographic.

\section{Introduction}

The regulations and laws governing the world of anti-money laundering processes are extensive, and the literature surrounding the field even more so. Particularly with regards to the literature, there are a number of theoretical perspectives advanced for either how to progress the system of anti-money laundering, or to show why the current system is ineffective. In this article however we will be examining a practical response to perceived issues within the AML process from the private sector. By adapting the model utilised so successfully by the leading credit rating agencies, the new offering Sigma Ratings exists to compliment the current AML regime by injecting independent and quantifiable data into the process so that associated parties may be more efficient in the battle against money laundering.

Theoretically this new offering is very welcome. The potential in allowing associated parties to become more efficient in dealing with entities that may be used as vehicles for money 
laundering is positive. However, there are a number of issues to examine before declaring whether this new venture will be a success, both from the side of Sigma and its model, and also from the side of its potential role in the AML environment. In order to remain focused on the task at hand, this article will concentrate on the role that banks play in the AML regime, mainly because a large bank is funding the new offering (Barclays), a number of banks have recently been financially punished for their failings within the AML regime, and also because the banking industry has been identified in the literature as a particularly important 'pinchpoint' for which money laundering can occur. The article will progress on the basis of first presenting the concept of money laundering and the fight against it, which will allow us to understand clearer the need to focus on the banking industry. To accompany that analysis, the article will continue by examining the role of the banking industry in more detail, so that we may better understand the potential role of Sigma Ratings. That will allow us to both examine Sigma Ratings' offering in the right context, but also ascertain its chances of succeeding based upon its prospective model. In adjoining that analysis to a discussion on the inherent issues within the concept of credit rating as an agency, as Sigma have essentially copied the same model, the article will conclude by discussing some potential concerns that Sigma may have to overcome in order to provide the AML regime with the assistance it claims it can.

\section{Money Laundering and the Fight against It}

It is far beyond the scope of this article to review the literature on money laundering. Even though money laundering as a concept is only around 30 years old, most countries around the world now have anti-money laundering legislation and regulation and there is a gluttony of associated literature to help us understand it (Booth et al., 2011). Yet, there are a number of definitions and theoretical constructs that can help us build a picture as to why an organisation like Sigma may be helpful. Booth et al discuss how the late 1980s laid the groundwork for the AML regime we know today as a response to the 'immense profits being made by drug cartels in South America and elsewhere' (ibid). Gilmour continues this line of reasoning by suggesting that "manifested from a need to secure the profitability and the enjoy-ability of illicitly gained financial funds, money laundering has become instrumental in both the success and collapse of organised crime' (Gilmour, 2016a). That suggestion is confirmed when we consider that global estimates have indicated that more than a trillion 
dollars has been laundered (which equates to $2.7 \%$ of global GDP) and that the industry of money laundering is the world's third largest behind oil and agriculture (Gilmour, 2016b).

It has been argued that there is a common core amongst the variety of jurisdictions that implement AML procedures and that they all mostly derive from the 40 Recommendations of the Financial Action Task Force (FATF). That common core can be broken down into three distinct sections of a 'three-stage process': Placement; Layering; and Integration (Booth et al., 2011). Placement describes the process whereby large amounts of cash are deposited into the banking system. It has been noted that this has become increasingly difficult over times as the AML requirements on banks grow stronger and stronger. It has also been noted that 'smurfing', which describes the process whereby small amounts of money will be deposited with a bank over time to disguise the large amount, is also becoming increasingly difficult. The second stage is to 'layer', which describes when repeated transfers of money are undertaken between accounts with financial institutions in different jurisdictions. This usually takes place within jurisdictions with poorer AML requirements as the aim is to conceal the criminal origin of the funds via the organisational capacity of the institution. Finally, to complete the process, the now apparently clean money is placed in a reputable bank or financial institution from which the funds can now be withdrawn and invested in the manner the criminal enterprise sees fit (ibid).

Since the 1980s when drug cartels became the inspiration for a new concerted effort to battle the laundering of illicitly-gained money, there has been a development that has created just as much attention. Terrorist financing is now just as important as any other source of money laundering and the FATF have developed 9 Recommendations on how to fight it. Terrorist financing is very different to the usual type of money laundering institutions have to battle against, in that whilst money laundering is about the cleansing of dirty money to be used legitimately, terrorist financing is about the misuse of clean, or dirty, money for terrorist purposes. Whilst normal money laundering has a number of related effects, but which need to be sought out in order to examine them i.e. the potential statistical impact of the loss of tax revenue, or the proliferation of criminal enterprises, for example, the results of terrorist financing have a clearly demonstrable effect once a terrorist attack takes place (ibid). Furthermore, this sentiment has been developed with the increase in international sanctions 
against countries like Iran for financing terrorism, or against countries like North Korea for nuclear proliferation (Levin et al., 2016). The picture this paints is one of tremendous complexity that financial institutions have to face in a number of elements of their business. It is apparent that the understanding of AML can be differentiated between that of the perpetrator and that of the institution who would be utilised as the vehicle for laundering money.

This dichotomy is represented in the literature. The concept of money laundering has been analysed from within a massive number of parameters, including Game Theory, Systems Theory, Evolutionary Game Theory, Self-Protecting Theory, and many more. In this article we shall focus on a small number of associated theories, and demonstrate that there is a contrasting view in the literature between that of the actions of the individual(s) who seeks to launder money, and that of the system designed to prevent that from happening. A Game Theory approach suggests that people and organisations involved in the instance of money laundering can be represented within a 'game' like scenario, where avoidance of detection and the rewards for doing so are counterbalanced by the penalties that have been developed. Not only does this apply to the criminal entities who must launder their money before they spend it, but to the banks who have to weigh up the costs of non-compliance, or at least a reduced level of compliance, against the financial recompense of being involved in the \$1 trillion-plus marketplace (Jayantilal et al., 2017). This is not to say that Banks wilfully partake in money laundering of course, because for one they have the potential reputational impact on top of any regulatory impact to consider, but the costs of compliance may be too high against the lack of any recompense for diligent compliance. Araujo (2010) suggests that this model is better suited to the 'Evolutionary Game Theory' model on account of the massive number of factors that impact upon the players within this 'game'. Not only do the organisations have to consider a number of variables with regards to their approach to battling money laundering, but the organisation's many employees have to consider a number of variables also, and particularly those within compliance departments. There may be a personal cost for being too stringent, but that is counterbalanced by a regime that is particularly punitive towards compliance professionals which may lead to a lack of compliance, according to Georgiou (2017). 
However, whilst some theorists examine the roles of individuals and organisations, others prefer to focus on a much bigger picture. It has been suggested that anti-money laundering 'is a demanding research domain that is interdisciplinary in its core' (Demetis, 2010) and Demetis subscribes to a theory that he argues is an amalgamation of a number of those disciplines. Systems Theory, as Demetis understands it, is a 'collection of highly abstract concepts that can be applied to a series of problem domains' and that, if used appropriately, 'can give considerable insights' (ibid). With regards to AML, the Systems Theory can be understood by first assessing an oversimplification. In separating the regulation of the field into three categories - local, national, and transnational -we can witness an AML hierarchy that functions according to a designed set of well-specified rules; where there is a problem, that problem will be overcome by specifying more rules, and failing that by formal legislation. That tiered process starts with organisations like the FATF, the EU, the UN, the IMF and so on. The authority that emanates from that level is deemed to be constitutive of the broader AML domain, which is why it is responsible for norm-setting (ibid). In terms of implementing those norms, national-level organisations like Central Banks come into play and implement the norms in relation to the culture they operate in. These national-level players are also in charge of monitoring the local level players, like local banks. However, Systems Theory argues that this is far too simple for something as complex as the AML regime, on account of the large number of external factors that affect the entire domain. Demetis suggests that it may be better to think of it in terms of overlapping subsystems - the legal subsystem, the economic subsystem, and the political subsystem. The theory is that whilst these subsystems have their own complexities, they can penetrate each other via communication and, as a result, create a new structure. With AML sitting in between these three structures, the result is for all three to inform the development of the AML structure. The political informs AML via the momentum to develop the structure, via such aspects as political action. If we think of the Trump Administration's focus on Iran and imposing sanctions for terrorist financing, we can see here a stimuli that informs the process and starts the mechanism (Ritter, 2018). The economic system informs the process via the rules relating to the vehicles within the AML domain, like banks and other financial institutions for example. Finally, the legal system informs the AML domain via the concept of illegality and, thus, gives rise to the 'ontological status of money laundering' (Demetis, 2010). 
Accepting the importance of this Systems Theory viewpoint for one moment, it appears that a number of inefficiencies stem from a misunderstanding of the systemic nature of the AML domain. Chong and Lopez-De-Silanes (2015) question whether the legal sphere matters in the AML context because it tends to target the outcome of money laundering, rather than the reason for it - it focuses on the symptom, not the cause. Araujo (2010) argues that one aspect of any perceived failure of the AML regime is that it has failed to fully integrate the banking system as a result of prescribing the rules to it, rather than with it. We shall review the issue of the banking sector shortly, but the inefficiencies are essentially systemic inefficiencies stemming from a lack of cohesion within the system. Systems Theory is easily applied to the domain of AML although there is room for other considerations.

Before we analyse the role of the banking industry, there are a number of theoretical perspectives that demonstrate both the importance of the sector to the AML regime, but also the difficulties that the sector face. Demitis and Angell (2007) discuss how, if one considers the AML regime from a System perspective, the system can be differentiated by a distinction between suspicious and non-suspicious, and the consequences of distinction. Whilst there are some base rules on what constitutes suspicious behaviour, it is still far too subjective in order for the regime to be clinical. Furthermore, whilst banks are subjected to an array of different regulations and laws, it is has been noted that there is a massive divergence in terms of contextualised expectation. For example, Ebikake (2016) identifies that whilst the common understanding of 'soft law' is that one is given a 'considerable degree of discretion as regards implementation', the reality within the AML regime is that such 'soft laws' are incredibly prescriptive and detailed, arguably rendering them as 'hard law'. Ebikake positions this against the theoretical resolutions developed by positivists like H.L.A. Hart, but in doing so develops the idea that it is important, potentially, to be descriptive within the AML regime because of the broadness of the system. In developing the criminological theory of situational crime prevention however, Gilmour (2016b) reaffirms the importance of the banking sector to the AML regime and the reason for why so many rules and regulations operate through the banking sector. He states that the underlying basis of situational crime prevention theory is to assess the entire environment within the given area, in this case money laundering, and develop a methodology that identifies 'points of intervention' so that the system can capture multiple versions of the same crime at once, rather than aim for just one crime. This is rational in that there are a number of versions of financial crime that need to be eradicated. It 
should be obvious that one of the best 'points of intervention' available to the AML regime, or 'choke-points' (Campbell-Verduyn, 2018), is the banking sector and, as such, it has been moved into the central position in the fight against money laundering. However, there are a number of issues with this, and the facts that money laundering is continuing almost unabated and the banks are receiving massive fines for non-compliance suggest that the current system is inefficient. As Sigma aims to increase that inefficiency, it is worth examining the role of banks before we are introduced to Sigma and its offering to the marketplace.

\section{The Role of the Banking Sector}

As stated above, the banks are considered as 'choke-points' for the delivery of AML procedures. Theoretically, this makes sense. However, in practice, the situation is much different. The underlying reason for this is that banks are for-profit private institutions for the most part, and complying with such an array of rules is a costly business. It has been noted that the banks were 'unwillingly recruited' (Bello, 2017) into the AML regime, and if we consider the length and breadth of the rules and regulations that the sector must comply with, or face massive penalties, it is not hard to see why.

In contrasting the Systems Theory viewpoint discussed earlier, Georgiou (2017) suggests that the co-mingling of the political and economic spheres is actually an example of 'government failure' or 'overreach' in that the political sphere has developed a new strand to be developed without any economic foundation. He talks specifically of the War on Terror engaged in since the attacks of 9/11, which has seen a massive increase in resources to fight such aspects of money laundering, but has seen 'no evident reduction in illicit money flows worldwide'. The suggestion is that this is also down to a conflation of terminologies in the sector, with a number of aspects being defined as 'money laundering', but also that current efforts are being driven by the fear associated with anti-terror initiatives rather than white-collar crime, which Georgiou argues may be the reason why banking staff are less likely to fully pursue an AML issue in that particular field. Yet, he is clear that financial intermediary 'agents' have been caught in the middle of the rush to develop AML regimes that are effective, and that this goes against the self-perceived role of the sector. If the sector do see themselves as 'facilitators' 
rather than 'policemen', then engaging them in the mould the norm-setters require will be particularly difficult.

It is in those norms, developed from the transnational entities and implemented by national bodies, that we see where the problem lays when applied by private entities. One of the most well-known concepts within the AML framework is the concept of 'know-your-customer' (KYC). This term describes when a bank must verify a customer's identity and monitor their transactions if a suspicion is raised. This also applies to 'smurfing', and then also to larger issues such as those who have been placed on a 'blacklist' via some sanction. This process is automated for the most part, but once certain criteria are triggered the bank's management are alerted and the decision is then made on whether to escalate the issue. This has had a number of connected consequences and many feed into a lack of engagement between the banks and the AML regime. The first is that private banking, or wealth management, is fundamentally affected by the process. Wealth management, which is lucrative for the banks, is based upon a traditional culture of confidentiality, 'difficulty in identifying beneficial owners, concealment (use of offshore trusts), banking secrecy, complexity of financial services and products, politically exposed persons (PEPs), high-value transactions, and multiple jurisdictions' (ibid). This issue of jurisdictional access is also massively important, especially in relation to Sigma Ratings and the current predicaments facing the banking sector, as 'Correspondent Banking' - banks that provide services in a certain jurisdiction on behalf of another bank (Tarbet and Liangshun, 2016) - is becoming one of the primary reasons for leading banks to fall foul of the AML regulations (Justice Department, 2012; Justice Department, 2015) and, potentially, one of the key ways in which Sigma can reduce costs and raise efficiency in the sector. In order for the banks to know they are complying with the AML regulations whilst undertaking aspects of wealth management or correspondent banking, they must perform either Customer Due Diligence (CDD), or Enhanced Due Diligence (EDD). CDD entails identifying the customer, verifying those details independently, and then understanding the nature of the business to be conducted. EDD however entails the same scrutiny initially, but then escalates to additional searches (adverse media perhaps) and then to a commissioned intelligence report. To accompany all of this the source of the funds in question must be independently verified. Georgiou discusses how the AML authorities will argue that the EDD is only required in a few cases and that the simplified due diligence is usually appropriate. However, the burden of proof is on the banks. 
All of this accumulates into the key sticking point with regards to the engagement of the banks with the AML regime - cost.

The vast amount of research needed to comply with AML regulations is having an adverse effect upon the costs of banking. Additionally, the compliance departments of the banks are being overburdened, and disproportionally so according to Georgiou, and to Levin et al (2018). Levin and her colleagues argue that there is a massive shift against compliance officials, with those officials being 'threatened with liability for failure to detect or prevent wrongdoing because of poor management, oversight, or program gaps' (ibid). They continue by discussing how even when compliance officers lack the necessary authority, regulators still expect them to educate senior executives and raise issues with senior management. Georgiou adds to this that the responsibility to train and inform relevant individuals falls on the compliance team and that they should have access to all of the information available to the business, across the domestic, international, and subsidiary businesses. This has naturally led to the banks complaining of the increased costs and burden placed upon them. In response, the AML domain has attempted to sweeten the deal for the banks by offering them something in return. There is a concerted push to open up traditionally untapped markets to the banks - termed by some as 'banking the unbanked' - via an initiative called 'Financial Inclusion' (FI). FI 'focuses on facilitating access to formal services for financial excluded and underserved groups, including low-income individuals, rural sectors, and undocumented groups. FI focuses on developing countries where the challenge is the greatest' (Georgiou, 2017). The suggestion when this was rolled out was that, via a concerted and verified riskbased approach, the people who FI captured would be so significant that the increased revenue from banking the un-banked would offset the costs of complying with regulations. In reality, this has not been the case and banks have taken a conservative approach in the face of such penalties - correspondent banking, and FI moreover, is actually reducing through fear of being penalised. This 'de-risking' is having a massive effect upon correspondent banking, which is affecting financial inclusion in the places that need it the most. However, the focus of this article is on introducing Sigma Ratings to the literature so that this market-based offering can be assessed against this backdrop of fundamental stumbling blocks within the AML system. 


\section{Sigma Ratings}

Sigma Ratings have a clear function. Whilst their composition and outward-facing branding mirrors that of the established credit rating agencies, the agency is determined to define itself. On its website, the agency declares that 'while we are a professional rating agency, we are different [from S\&P, Moody's, and Fitch] in that we are rating entity-level "non-credit" risks such as financial crime compliance and governance, whereas credit rating agencies are targeting credit issues such as solvency and likelihood of default' (Sigma Ratings, 2019). It is important to note immediately that this focus is something that the 'Big Three' credit rating agencies also focus upon, although their analysis of 'non-credit' risk factors are just some of many factors that factor into an overall credit rating. This is similar to the rating agencies' inclusion of ESG-related data, which is an element that has witnessed a number of dedicated Sustainability Rating Agencies emerge to offer the same, but perhaps more bespoke and clearer risk analysis, just like Sigma Ratings is doing for aspects such as the analysis of financial crime compliance (Cash, 2018a).

Sigma Ratings have a clear approach when it comes to advertising their unique offering to the marketplace. Again, on its website, the agency states that 'we are re-defining the way the world sees risk and are utilising deep domain expertise and cutting-edge computer science to both rate and generate risk scores on thousands of companies around the world'. The agency's co-founder, Mr Stuart Jones - a former US Treasury Official - makes this clearer when he states that 'this is the world's first business integrity rating agency' (Jenkins, 2018). This concept of 'business integrity' is, for the agency, related to a number of key financial aspects that face the global marketplace today. More specifically, the agency is focusing upon the compliance with financial crime regulation and legislation and other aspects such as internal governance, an entity's observance of financial sanctions, corruption, and an entity's overall reputation. The agency was developed by former US Treasury official Stuart Jones and Gabrielle Haddad, a former M\&A lawyer. At the time of writing, the team comprises of eight individuals, eight advisors - including former US Treasury official Robert Werner - and two experienced advisors who sit on the rating committee to 'ensure the quality' of the agency's methodology. Whilst still only a small team, the agency has developed a clear structure for arriving at its ratings. 
Sigma Ratings have adopted a similar rating scale to that of the established rating agencies ( $\mathrm{S} \& \mathrm{P}$ in particular). Its rating scale ranges from 'AAA' to ' $\mathrm{C}$ ', although they, as of yet, have not included additional identifiers like S\&P have; for example, there are no '+' and '-' adages, nor are there any additional identifiers such as 'creditwatches'. In terms of the rating process, the agency has what it calls a 'certification process', which consists of three major phases. Firstly, an entity will start the process by answering an online questionnaire about its customers, products on offer, internal policies, and staffing procedures. At this stage the entity will upload any relevant document to the agency that will assist with the rating examples may include documents relating to compliance. Once this has been completed, Sigma Ratings has a 'proprietary model' that it has developed which scores the answers of the questionnaire against pre-determined metrics. To verify the information, the information contained in the questionnaire is verified by a Ratings Analyst, and then there are series of interviews (three) between a Ratings Analyst and the entity in question. Then, moving to the final stage of the process, the rating and rating report is developed and delivered to the entity. That information is then available to investors, regulators, and anybody else who may be interested, although the report can remain private at the entity's request in order to be utilised internally. Finally, the agency declares that its ratings are refreshed annually.

Looking above, we can see that it is the entity that initiates the ratings procedure, and this is because the agency utilises the infamous 'issuer-pays' model that the 'Big Three' rating agencies utilise (Naciri, 2015). This model describes when, rather than investors paying to incorporate the rating information into their investment decisions, the rated entity is the one who pays the firm for the rating. This conflict of interest is perhaps the most examined with regards to the rating agencies, and has been identified as, perhaps, one of the principal causes of the degeneration of standards that led to the rating agencies' involvement in the financial crisis (Darbellay, 2013). However, it is worth considering the different dynamic at play with Sigma Ratings, as opposed to their credit rating brethren. It is true that a conflict of interest still remains with Sigma's utilisation of the model because, in what is a crude understanding, the agency may be inclined to produce favourable ratings for the paying entity. Yet, the end user is different with Sigma. Investors may well use Sigma's ratings to inform their decision about investing with a certain entity (let us say a large bank), but regulators have a much 
more prominent reason for using Sigma's ratings. It is imagined that Sigma's ratings will be used by rated entities to signal to regulators their compliance with certain rules, whilst it is also not unimaginable that regulators will use Sigma's ratings as 'benchmarks' for compliance rates with certain regulations. We will return to this potential outcome shortly, but the 'signalling' element described above is something that is inherently attached to the concept of rating and is the core of the concept known as 'rating addiction' (Cash, 2018b) - in terms of credit ratings, the rating can be used by managers to signal to disperse investors, used by investors to restrain management, or used by regulators to define certain practices within a given financial arena (they can also be used by 'issuers' to signal to investors and regulators) (Cash, 2018c).

Although the rated entities pay for the ratings produced by Sigma Ratings, the agency has received funding from a number of sources to begin its operations. Most noticeably, Barclays provided the agency with $\$ 2.4$ million from its fintech 'Accelerator programme' (who are among an early batch of firms incorporating Sigma's ratings), alongside TechStars, and a number of so-called 'angel investors' from the US and 'high growth emerging markets'. Interestingly, Sigma makes clear that, at the time of writing, it does not offer any advisory, consultancy, or ancillary services (a number of terms essentially describing additional, nonrating services) which have become particularly lucrative for the credit rating agencies (and which are highly contentious). It is worth discussing why Barclays have taken an interest in Sigma Ratings before we move on, as its injection of capital and adoption of the agency's ratings has proven to be a headline-creating boon to the new agency. In 2015, the bank was fined $£ 72$ million by British regulators for its 'poor handling of financial crime risks' (Jenkins, 2018) and, with its competitors HSBC and BNP Paribas being fined by American regulators $\$ 2$ and $\$ 9$ billion respectively, it is clear that the large financial institutions are recognising the importance of a. increasing the amount of information in relation to financial crime within their systems and b. transmitting this new developed approach to external bodies, such as regulators. It is this facet of Sigma's offering, namely that one can transmit compliance via a rating, that is likely to be its biggest asset.

Nevertheless, the new rating agency offers something particularly novel to the financial arena. The ever-increasing focus on financial crime and its wider impact is clearly on the 
regulatory agenda. Recent fines describe for us an increased focus, and when we take into consideration an ever-changing geo-political landscape that is being dominated by financial sanctions (think of the US' sanctioning of Russian and Iranian bodies, for example), it is becoming ever more important that large financial institutions both avoid such financial practices but more importantly are able to definitively transmit this avoidance to external bodies. If we return to the concept of Correspondent Banking quickly, the larger banks are at the mercy of AML and financial crime compliance practices within the correspondent banks that are not always evident. It is believed that ratings such as those produced by Sigma Ratings will allow the larger banking institutions to monitor their smaller affiliates much more efficiently.

Though Sigma Ratings is the focus of this article, in truth there is little to report at the moment. The operation is barely underway and it is merely in the process of collaborating and spreading the word of its model across the business world. For us however, it is worth just reminding ourselves of some of the potential benefits and drawbacks of this new offering. The biggest potential benefit by far is that the agency can serve to reduce the costs for banks and their AML compliance by injecting independent information into the system. It is not unfathomable that, if Sigma begins to build a reputation, regulators will allow for Sigma's ratings to displace some of the due diligence that Banks must undertake. However, this potential benefit is fundamentally tied to a potential flaw. We have seen in the credit rating industry how tying regulatory practices to external and private ratings can lead to massive contagion, like that witnessed in the Financial Crisis - every organisation that had to invest in AAA-rated securities, for example, did just that. The problem was that the rating agencies had inflated their credit ratings, within the RBMS market, across the board so when a number of securities collapsed, what was to follow was inevitable. If the same thing were to happen with Sigma, one could see a massive global issue occur given the connected nature of money laundering as a concept. We have discussed already how the economic, legal, and political are all intertwined in this arena, so a failure could lead to massive repercussions for society. If we connect to this the potential for Sigma to follow the pathway developed by the agencies and, as investigations from the Crisis have revealed, essentially seek to favour the paying client over everybody else (by way of ratings inflation or the production of ancillary/consultancy services), then the effect could be just as dire. Yet, there is a real 
opportunity for Sigma to positively affect the marketplace with a model that is novel, exciting, and above all needed.

\section{Conclusion}

The world of money laundering and the fight to stop it has been developing at quite a pace. In just over thirty years there is an established international collaboration aimed at providing a clear set of norms that are then implemented around the world. However, we have seen in this article that there are a number of key flaws which are prohibiting that ideal from being fully realised. One of the biggest flaws is that the AML regime is dependent upon the cooperation from the banks. Whilst the AML regime has sought to both compel and tempt the banks to cooperate, the core concept of a private company is trumping the full inclusion of the banks into the AML system. Arguably, this is to be expected, and whilst some may argue that there is an important social need for the banks to operate in a cooperative manner, there will be just as many arguing that as a private company a bank must look after itself. The reality is that when such a deadlock occurs there may need to be small operations that help to ease the process for all concerned, and in Sigma Ratings there exists this potential. Whilst Sigma Ratings is brand new and more research will be needed once it develops, the market-based solution to the core problem within the AML sphere may just work. 


\section{Bibliography}

Araujo, R.A. (2010) “An Evolutionary Game Theory Approach to Combat Money Laundering” Journal of Money Laundering Control Vol. 13 No. 1 70-8.

Bello A.U. (2017), Improving Anti-Money Laundering Compliance: Self-Protecting Theory and Money Laundering Reporting Officers, Springer, Switzerland.

Booth, R., Bastable, G., and Yeo, N. (2011), Money Laundering Law and Regulation: A Practical Guide, Oxford University Publishing, Oxford.

Campbell-Verduyn, M. (2018) "Bitcoin, crypto-coins, and global anti-money laundering governance" Crime, Law and Social Change Vol. 69 No. 2 283-305.

Cash, D. (2018a) The Role of Credit Rating Agencies in Responsible Finance, Palgrave Macmillan, Switzerland.

Cash, D. (2018b) "Sustainable Finance Ratings as the latest Symptom of "Rating Addiction"” Journal of Sustainable Finance \& Investment Vol 8 No. 3 242-258.

Cash, D. (2018c) Regulation and the Credit Rating Agencies: Restraining Ancillary Services, Routledge, Oxford.

Chong, A., and Lopez-De-Silanes, F. (2015) "Money Laundering and its Regulation" Economics and Politics Vol 27. No. 1 78-123.

Darbellay, A. (2013) Regulating Credit Rating Agencies, Edward Elgar, Cheltenham.

Demetis, D.S. (2010) Technology and Anti-Money Laundering: A Systems Theory and RiskBased Approach. Edward Elgar, Cheltenham.

Demetis, D.S., and Angell, I.O. (2007) “The risk-based approach to AML: Representation, Paradox, and the $3^{\text {rd }}$ Directive" Journal of Money Laundering Control Vol. 10 No. 4 412-428. Department of Justice, (2012) "HSBC Holdings Plc. and HSBC Bank USA N.A. Admit to Anti-Money Laundering and Sanctions Violations, Forfeit \$1.256 Billion in Deferred Prosecution Agreement" available at https://www.justice.gov/opa/pr/hsbc-holdings-plc-andhsbc-bank-usa-na-admit-anti-money-laundering-and-sanctions-violations (accessed 15/04/2019). 
Department of Justice, (2015) "BNP Paribas Sentenced for Conspiring to Violate the International Economic Powers Act and the Trading with the Enemy Act" available at https://www.justice.gov/opa/pr/bnp-paribas-sentenced-conspiring-violate-internationalemergency-economic-powers-act-and (accessed 15/04/2019).

Ebikake, E. (2016) "Money Laundering: An assessment of soft law as a technique for repressive and preventive anti-money laundering control" Journal of Money Laundering Control Vol. 19 No. 4 346-75.

Georgiou, G.C. (2017) "Beyond the Shadow Economy: Anti-money Laundering and Combating the Financing of Terrorism" World Economics Vol 18. No. 3 155-202.

Gilmour, N. (2016a), "Understanding the Practices Behind Money Laundering - A Rational Choice Interpretation” International Journal of Law, Crime and Justice Vol. 44 1-13.

Gilmour, N. (2016b), "Preventing money laundering: A test of situational crime prevention theory" Journal of Money Laundering Control Vol. 19 No. 4 376-396.

Jayantilal, S., Jorge, S.F., and Ferreira, A. (2017) "Portuguese Anti-money Laundering Policy: A Game Theory Approach” European Journal on Criminal Policy and Research Vol. 23 No. 4 559-574.

Jenkins, P. (2018) “World's first “Integrity Rating” Agency Launched” Financial Times, 2 July.

Levin, S.C., Gutierrez, F.H., Carroll, K., and Alper, E. (2016), “Anti-money laundering and sanctions compliance challenges for custody services" Journal of Securities Operations \& Custody Vol. 8 No. 4 341-356.

Levin, S.C., Hogan, E.J., and Kaplan-Marans, T. (2018) “Anti-Money Laundering Enforcement: The Rise of Individual Liability for Compliance Professionals" Journal of Taxation and Regulation of Financial Institutions Vol. 31. No. 4 5-13.

Naciri, A. (2015) Credit Rating Governance: Global Credit Gatekeepers, Routledge, Oxford. Ritter, S. (2018), Dealbreaker: Donald Trump and the Unmaking of the Iran Nuclear Agreement, SCB, Atlanta.

Sigma Ratings, (2019) “About Us”, available at https://www.sigmaratings.com/about-us (accessed 15/04/2019). 
Tarbet, H.P., and Liangshun, Q. (2016), "The Perils and Promise of Correspondent Banking" The Banking Law Journal Vol 133, No. 2 53-67. 